\title{
Association Between the Corrected QT Interval and Carotid Artery Intima-Media Thickness in Obese Children
}

\author{
Ayla Güven, Tolga Özgen*, Olcay Güngör*, Murat Aydın*, Kemal Baysal** \\ Göztepe Educational and Research Hospital, Clinics of Pediatric Endocrine, Istanbul, Turkey \\ * Ondokuz Mayıs University Medical Faculty, Department of Pediatric Endocrinology, Samsun, Turkey \\ **Ondokuz Mayıs University Medical Faculty, Department of Pediatric Cardiology, Samsun, Turkey
}

\begin{abstract}
Objective: Sudden death has been reported in asymptomatic obese adults and the mechanism is unclear. In recent years, obesity has shown a dramatic increase in children and this enhances the risk factors for the development of cardiovascular disease. The aim of this study was to investigate whether there is repolarization abnormality and any potential risk factor such as increase in intima-media thickness (IMT) of carotid artery for corrected QT (OTc) prolongation among obese children.

Methods: A total of 60 obese children, 30 of which had features of metabolic syndrome (MS), and 23 age-matched controls were included in the study. OTc interval was calculated at rest. The IMT of both common carotid arteries (CCA) was measured. The relationship between QTc, IMT of right and left CCA and insulin sensitivity indices were evaluated in the study group.

Results: The OTc interval of the children with simple exogenous obesity (SEO) were longer than in the controls $(p=0.024)$. The IMT of both carotid arteries of the obese girls and boys with and without MS were higher than the controls $(p=<0.001)$. The OTc was significantly affected by the parameters pertaining to the right carotid artery IMT, to chronologic age and HDL-C.

Conclusion: Since obesity may cause subclinical atherosclerotic disease regardless of sex, obese children must be followed closely for early cardiovascular problems.
\end{abstract}

Key words: Obesity, QTc, carotid artery intima-media thickness

Received: 28.11.2009

Accepted: 16.12 .2009

\section{Introduction}

The prevalence of childhood obesity is increasing rapidly, particularly in developed countries. It has also been shown that increased frequency of obesity in children parallels the increase in risk factors for the development of cardiovascular diseases (1-3). Sudden death has been reported in obese adults who have no apparent heart abnormalities; the mechanism is unclear (4). Results of studies concerning prolongation of the corrected OT (OTC) in obese adults are controversial (5-7). It has been shown that adults with metabolic syndrome (MS) have higher values of OTc-min and QTc-max (8). The QT dispersion (QTc-d) has been suggested as a physiological variability of regional ventricular repolarization. Physiological hyperinsulinemia acutely prolongs ventricular repolarization independent of insulin sensitivity (9). QTc prolongation and increased QTc-d have been reported in children with type 1 diabetes, but the mechanism remains unknown (10). Also, it has been shown that QTc interval prolongation in adults with type 2 diabetes is associated with ischemic heart disease (11), and that patients with prolonged QTc interval have higher mortality from cardiovascular disease (12).

Obese children have endothelial dysfunction associated with fatty streaks and fibrous plaques $(13,14)$. They are also at increased risk for coronary artery calcification and coronary heart disease in adulthood $(15,16)$. Carotid artery intima-media thickening (IMT) provides an indirect assessment of coronary disease. In adults, there is a strong association between coronary vascular disease and carotid

\section{Address for Correspondence}

Ayla Güven, Göztepe Educational and Research Hospital, Clinics of Pediatric Endocrine Kadıköy, Istanbul, Turkey

Phone: +90 5322380300 Fax: +90 2165664023 E-mail: aylaguven@yahoo.com

(c) Journal of Clinical Research in Pediatric Endocrinology, Published by Galenos Publishing. 
artery IMT $(17,18)$. Carotid artery IMT also progresses faster in the presence of coronary artery disease (19). The echocardiographic measurement of carotid artery IMT is useful in showing generalized atherosclerosis $(18,20)$. A positive correlation was found between carotid artery IMT and prolonged QTc (21).

The aim of the present study was to investigate whether there is repolarization abnormality in obese children. The potential risk factors for QTc prolongation in these children have also been investigated.

\section{Methods}

A total of 60 asymptomatic obese children and adolescents [13.3 \pm 2.4 (range 8.2-17.7) years] and 23 age-matched controls [12.94 $\pm 2.43(6.1-16.2)$ years] were included in the study. Patients followed in the endocrinology outpatient clinic for short stature and who were free of any cardiac symptom constituted the control group. There were no children in the study or control groups who were on any medication known to modify the QT interval.

The height and weight of all individuals were recorded between 09.00 and 12.00 am and their body mass indices (BMI) were calculated. All subjects in the study group had $\mathrm{BMI}$ values exceeding the $95^{\text {th }}$ percentile for age and sex, and all were classified as obese (22).

Blood pressure was measured in sitting position in the right arm with a mercury sphygmomanometer following a 15-minute rest period. Mean arterial pressure (MAP) was calculated with the following formula (23).

Diastolic blood pressure (DBP)+[systolic blood pressure (SBP)-DBP)]/3

All subjects having a SBP and/or DBP higher than the $95^{\text {th }}$ percentile for age and sex were classified as hypertensive (24).

After routine physical examination, a resting 12-lead electrocardiogram with a rhythm strip was recorded during the same time interval (09.00-12.00 am). This standard 12-lead electrocardiogram was performed with a paper speed of $25 \mathrm{~mm} / \mathrm{sec}$ and amplitude of $10 \mathrm{~mm} / \mathrm{mV}$ (Schiller AT-2 plus, Switzerland); 5 consecutive beats were evaluated on lead II rhythm strip. The QT interval was taken as the value from the beginning of the QRS complex to the end of the down slope of the $T$ wave (crossing of the isoelectric line). The QTc for the previous cardiac R-R cycle length was calculated according to Bazett's formula (25). The QTc-d was calculated as the difference between the longest and the shortest QTc interval, measured in each of the 12 electrocardiographic leads. Two physicians measured all the intervals; to minimize interphysician variability, the mean of the two calculations has been used for analysis. A QTC $>440$ ms was considered abnormally prolonged, according to the commonly used criteria (26).
Echocardiographic studies were performed with ATL HDI 3000 CV system (ATL, Germany). Subjects were examined in a supine position. A longitudinal view of the distal common carotid artery was obtained from the suprasternal notch using a 3-5 $\mathrm{MHz}$ sector transducer. The IMT measurements were made in both carotid arteries at about $2 \mathrm{~cm}$ after the bifurcation. All measurements were repeated twice by the same observer.

Fasting ( $\geq 10$-hours) blood samples were obtained from all subjects, in the study population for measuring the levels of glucose, insulin, total cholesterol (TC), triglyceride (TG) and high-density lipoprotein-cholesterol (HDL-C). Low-density lipoprotein (LDL-C) concentration was calculated by using the Friedewald equation [LDL-C=TC- (HDL-C -(TG/5)] (27). After a high- carbohydrate diet $(300 \mathrm{~g})$ for 3 days and an 10-hour overnight fasting, oral glucose tolerance test (OGTT) was performed in all obese children $(1.75 \mathrm{~g} / \mathrm{kg}$ body weight, maximum $75 \mathrm{~g}$ glucose) and the venous blood glucose and insulin levels were determined at 0, 30, 60, 90 and 120 minutes. OGTT was not performed in the control group for ethical reasons. Homeostatic model assessment (HOMA-IR) was calculated as the product of the fasting plasma insulin levels $(\mu \mathrm{l} \mathrm{U} / \mathrm{mL})$ and fasting plasma glucose levels (mmol/L), divided by 22.5 (28). Fasting glucose/insulin ratio (FGIR) was calculated from the fasting plasma glucose and serum insulin levels. Quantitative insulin sensitivity check index (QUICKI) was determined by the formula (29).

$1 /[$ Log fasting insulin $(\mu \mathrm{U} / \mathrm{mL})+\log$ fasting glucose $(\mathrm{mg} / \mathrm{dL})]$

Serum glucose was measured by enzymatic-spectrophotometric glucose oxidase method (Roche Diagnostics, USA). Insulin was assayed by chemiluminescence method using the commercial kit from DPC (Diagnostic Products Corporation, USA). Lipid parameters were determined by enzymatic methods using commercial kits. All analyses were performed by using standard instruments (Roche/ Hitachi 917, Japan). Serum levels of TC, TG and HDL-C were also measured by the Roche Diagnostics system.

A global risk factor cluster score was assigned to each participant on the basis of presence or absence of up to 5 age-adjusted risk factors: obesity, high serum fasting insulin level (>15 $\mu \mathrm{lU} / \mathrm{mL})$, high TG level (>100 mg/dL), high LDL-C level (>130 mg/dL), low HDL-C level ( $<40 \mathrm{mg} / \mathrm{dL}$ ) and high blood pressure (either SBP or DBP). $\mathrm{MS}$ in children was defined as having at least three of the defined risk criteria $(30,31)$. According to these criteria, the obese children were divided into two groups as MS and simple exogenous obese (SEO).

\section{Statistical Analysis}

Statistical analysis was performed using SPSS 10 Statistical Software Package (SPSS Inc., Chicago, IL, USA). Auxological data, SBP, DBP, MAP and hormonal results were expressed as mean $\pm S D$, unless otherwise stated. Normality of the data was evaluated by the "Kolmogorov Smirnov test". Differences in the parameters between 
obese groups were investigated using the independent samples t-test. One-way analysis of variance followed by the least significant difference post-hoc test (LSD) was used to assess the significance of the differences in QTC, QTc-d, right and left carotid IMT in the obese and control groups. Pearson's $r$ and Kendall's tau-b correlation coefficients were used for the analysis of intercorrelations among the investigated parameters. Linear regression analysis was applied to carotid artery IMT (mm) and QTc (msc) data. A $p<0.05$ was considered statistically significant.

\section{Ethics}

Approval for the study was obtained from the Institutional Review Board of the Ondokuz Mayıs University Faculty of Medicine. The purpose of the study was explained to all subjects before participation and written informed consent was obtained from the parents of the study and the control groups.

\section{Results}

Table 1 shows the anthropometric (weight, height, BMI) and clinical characteristics of the study population. There were no differences between the two sexes in clinical and laboratory parameters.

The values of systolic blood pressure, HOMA-IR, fasting insulin, glucose at 120 minutes and insulin at 120 minutes were higher in the MS group than in the SEO. The QUICKI value of the MS group was lower than that of the SEO group and the controls (Table 1 and 2). Twenty seven (18 female) obese children had hypertension. Twenty (81\%) of these children had findings consistent with other criteria of MS.
QTc duration ranged from 0.337 to $0.427 \mathrm{~ms}$ in $\mathrm{MS}$ group; from 0.347 to 0.455 in SEO group. The QTc of the obese patients was longer than the controls $(p=0.024)$ (Table 3). Also, five of the SEO girls had long OTc (16.6\%). QUICKI and FGIR were negatively correlated with OTC $(r=-0.268, p=0.041)$ in the obese children.

The IMT of the study population was evaluated after adjustment for BMI. The IMT measurements of both carotid arteries in the obese groups were higher than the controls ( $p<0.001)$ (Table 3).

Both right (RCA) and left carotid artery (LCA) IMT values were higher in both male and female obese children when compared with controls (Figure 1 and 2). The minimum and maximum values of the RCA-IMT in the study group were 1.19-2.47 mm in obese children with MS, $1.29-2.65 \mathrm{~mm}$ in the SEO group and $0.73-1.21 \mathrm{~mm}$ in the control group. The minimum and maximum values of LCA-IMT in study groups were 1.22-2.52 $\mathrm{mm}$ in the obese with MS, 1.31-2.65 $\mathrm{mm}$ in the SEO group and $0.75-1.23 \mathrm{~mm}$ in the control group. The youngest child in the study group was a 8 7/12 year-old girl, who had MS and had higher LCA and RCA-IMT values than the control group (RCA- IMT was $1.30 \mathrm{~mm}$, and LCA-IMT $1.33 \mathrm{~mm}$ ). HOMA-IR showed a statistically significant correlation with RCA-IMT $(r=0.432, p=0.001)$ (Figure 3$)(r=0.276, p=0.033)$ in the obese group.

QTC was negatively correlated with QUICKI ( $r=-0.268$, $p=0.041)$ and FGIR $(r=-0.268, p=0.041)$ in the obese children. OTC was significantly affected by RCA-IMT, chronologic age and HDL-C levels, according to the results of stepwise linear regression analysis (Table 4). RCA-IMT was the statistically significant determinant for LCA-IMT according to the multivariate linear regression analysis in both obese groups. BMI and LCA-IMT were the statistically significant determinants for RCA-IMT according to the multivariate linear regression analysis (Table 5).

Table 1. Anthropometric and clinical features of the study population

\begin{tabular}{|c|c|c|c|c|}
\hline & $\begin{array}{l}\text { Total obese } \\
n=60\end{array}$ & $\begin{array}{l}\text { Obese with } \\
\text { Metabolic Syndrome (MS) }\end{array}$ & $\begin{array}{l}\text { Obese with Simple } \\
\text { Exogenous Obesity (SEO) }\end{array}$ & Controls \\
\hline Number (Female/Male) & $38 / 22$ & $20 / 10$ & $18 / 12$ & $14 / 9$ \\
\hline Age, years & $13.3 \pm 2$ & $13.3 \pm 2$ & $13.3 \pm 2$ & $12.9 \pm 2$ \\
\hline Height, cm & $157.3 \pm 9$ & $157.7 \pm 9$ & $156.9 \pm 8.3$ & $152.2 \pm 12$ \\
\hline Weight, kg & $78.4 \pm 20$ & $80.2 \pm 22^{a}$ & $76.6 \pm 18^{a}$ & $44.1 \pm 91$ \\
\hline BMI, $\mathrm{kg} / \mathrm{m}^{2}$ & $31.1 \pm 5.5$ & $31.5 \pm 5.8^{\mathrm{a}}$ & $30.7 \pm 5.2^{\mathrm{a}}$ & $18.8 \pm 2.1$ \\
\hline $\mathrm{SBP}, \mathrm{mmHg}$ & $126 \pm 16$ & $131 \pm 18^{a, b}$ & $122 \pm 12^{a}$ & $103 \pm 10$ \\
\hline $\mathrm{DBP}, \mathrm{mmHg}$ & $79 \pm 12$ & $79 \pm 12^{\mathrm{a}}$ & $79 \pm 11^{\mathrm{a}}$ & $66 \pm 5$ \\
\hline MAP, mmHg & $95 \pm 11$ & $96 \pm 13^{a}$ & $94 \pm 10^{\mathrm{a}}$ & $78 \pm 7$ \\
\hline
\end{tabular}




\section{Discussion}

In the present study, we investigated the effects of clinical and laboratory findings of obese children on the prolongation of QTC and on IMT in both carotid arteries. The prolongation of QTc was mostly affected by chronological age, HDL-C and RCA-IMT in the obese children. Also, lengthening of QTC showed a negative correlation with QUICKI and FGIR in the obese children. There was no statistically significant association between QTc-d and cardiovascular risk factors such as hypertension, insulin resistance and dyslipidemia. We found also a negative correlation between HDL-C and the IMT values of both carotid arteries and BMI in the obese children. OUICKI and FGIR were negatively correlated with IMT of both carotid arteries and also with $\mathrm{BMI}$ in the obese children in our study. These results confirmed that insulin resistance associated with decreased serum HDL-C is a risk factor for atherosclerosis and prolongation of QTc, particularly in obese children even at young ages. Also, our results showed that obese children need to undergo cardiological examination, even in the absence of clinical symptoms, because lengthening of OTc can result in sudden death (4).

The IMT of carotid arteries in the obese children with and without MS were higher than those of the controls.

Table 2. Biochemical and hormonal parameters of the obese children with Metabolic Syndrome, Obese with Simple Exogenous Obesity and in the control groups

\begin{tabular}{|c|c|c|c|c|}
\hline & $\begin{array}{l}\text { Total obese } \\
n=60\end{array}$ & $\begin{array}{l}\text { Obese with Metabolic } \\
\text { Syndrome (MS) (n=30) }\end{array}$ & $\begin{array}{l}\text { Obese with Simple } \\
\text { Exogenous Obesity (SEO) }(n=30)\end{array}$ & $\begin{array}{l}\text { Controls } \\
(n=23)\end{array}$ \\
\hline Total cholesterol, mg/dL & $172 \pm 26$ & $170 \pm 23^{a}$ & $175 \pm 28^{a}$ & $140 \pm 25$ \\
\hline Triglyceride, mg/dL & $135 \pm 75$ & $153 \pm 82^{a}$ & $118 \pm 64^{d}$ & $76 \pm 25$ \\
\hline LDL-C, mg/dL & $102 \pm 11$ & $99 \pm 20^{\mathrm{a}}$ & $105 \pm 22^{\mathrm{a}}$ & $72 \pm 19$ \\
\hline $\mathrm{HDL}-\mathrm{C}, \mathrm{mg} / \mathrm{dL}$ & $43 \pm 11$ & $41 \pm 13^{c}$ & $46 \pm 8$ & $52 \pm 13$ \\
\hline Fasting glucose, $\mathrm{mg} / \mathrm{dL}$ & $86 \pm 8$ & $87 \pm 9$ & $86 \pm 6$ & $89 \pm 7$ \\
\hline Fasting insulin, $\mu \mathrm{U} / \mathrm{mL}$ & $30 \pm 19$ & $37 \pm 20^{\mathrm{a}, \mathrm{c}}$ & $23 \pm 13^{a}$ & $7.5 \pm 3$ \\
\hline Glucose 120 minutes, $\mathrm{mg} / \mathrm{dL}$ & $116 \pm 24$ & $123 \pm 27^{c}$ & $109 \pm 18$ & - \\
\hline Insulin at 120 minutes, $\mu \mathrm{U} / \mathrm{mL}$ & $124 \pm 92$ & $169 \pm 98$ & $79 \pm 60$ & - \\
\hline HOMA-IR & $6.5 \pm 4$ & $7.9 \pm 4^{\mathrm{a}, \mathrm{c}}$ & $4.9 \pm 3^{\mathrm{a}}$ & $1.6 \pm 0.7$ \\
\hline QUICKI & $0.300 \pm 0.02$ & $0.290 \pm 0.01^{a, b}$ & $0.311 \pm 0.02$ & $0.364 \pm 0.03$ \\
\hline FGIR & $3.93 \pm 2.2$ & $2.98 \pm 1.4$ & $4.88 \pm 2.4$ & $15.6 \pm 9.9$ \\
\hline \multicolumn{5}{|c|}{$\begin{array}{l}\text { QUICKI: Quantitative insulin-sensitivity check index } \\
\text { a: } p<0.0001 \text {, Children with MS and SEO vs Controls } \\
\text { b: } p<0.001 \text {, Children with MS vs SEO } \\
c: p<0.05 \text {, Children with MS vs SEO } \\
d: p<0.05 \text {, Children with MS vs Controls }\end{array}$} \\
\hline
\end{tabular}

Table 3. Echocardiographic and electrocardiographic parameters of the obese and control groups (Mean \pm SD)

\begin{tabular}{|c|c|c|c|c|}
\hline & $\begin{array}{l}\text { Total obese } \\
n=60\end{array}$ & $\begin{array}{l}\text { Obese with Metabolic } \\
\text { Syndrome (MS) }(n=30)\end{array}$ & $\begin{array}{l}\text { Simple Exogenous } \\
\text { Obesity (SEO) ( } n=30)\end{array}$ & $\begin{array}{l}\text { Controls } \\
(n=23)\end{array}$ \\
\hline Right carotid artery IMT*, mm & $1.61 \pm 0.28^{\mathrm{a}}$ & $1.63 \pm 0.3^{\mathrm{c}}$ & $1.59 \pm 0.2^{c}$ & $0.97 \pm 0.1$ \\
\hline Left carotid artery IMT*, mm & $1.65 \pm 0.28^{\mathrm{a}}$ & $1.67 \pm 0.2^{\mathrm{c}}$ & $1.63 \pm 0.2^{\mathrm{c}}$ & $1.0 \pm 0.1$ \\
\hline QTc, msec & $397 \pm 27^{b}$ & $391 \pm 20$ & $404 \pm 30^{d}$ & $377 \pm 44$ \\
\hline Dispersion of Qtc, msec & $0.045 \pm 0.04$ & $0.051 \pm 0.06$ & $0.040 \pm 0.02$ & $0.052 \pm 0.03$ \\
\hline \multicolumn{5}{|c|}{$\begin{array}{l}\text { Intima-media thickness (IMT) adjusted according to the body mass index (BMI) of the study population } \\
a: p<0.0001 \text {, Obese vs Controls } \\
b: p<0.05 \text {, Obese vs Controls } \\
c: p<0.0001 \text {, Children with MS and SEO vs Controls } \\
d: p<0.05 \text {, Children with SEO vs Controls }\end{array}$} \\
\hline
\end{tabular}


However, there was no difference between the values of carotid artery IMT in the children with and without MS. This implied that obesity alone may be associated with significant impairment of vascular functions.

In adults, compensatory hyperinsulinemia may lead to persistent QTc lengthening in insulin-resistant patients with obesity and diabetes, even in the absence of autonomic neuropathy (32). Insulin causes QTc prolongation directly or through sympathetic activation. It was shown that resting QTc positively correlated with fasting insulin in the adult population (4). Festa et al (21) found a significant relationship between heart rate-corrected OT interval and carotid atherosclerosis in nondiabetic subjects. These authors also suggested the QTc interval as a marker of undetected atherosclerotic disease. In our study, QTc was found to be significantly affected by RCA-IMT, chronologic age and $\mathrm{HDL}-\mathrm{C}$, according to the results of linear regression analysis

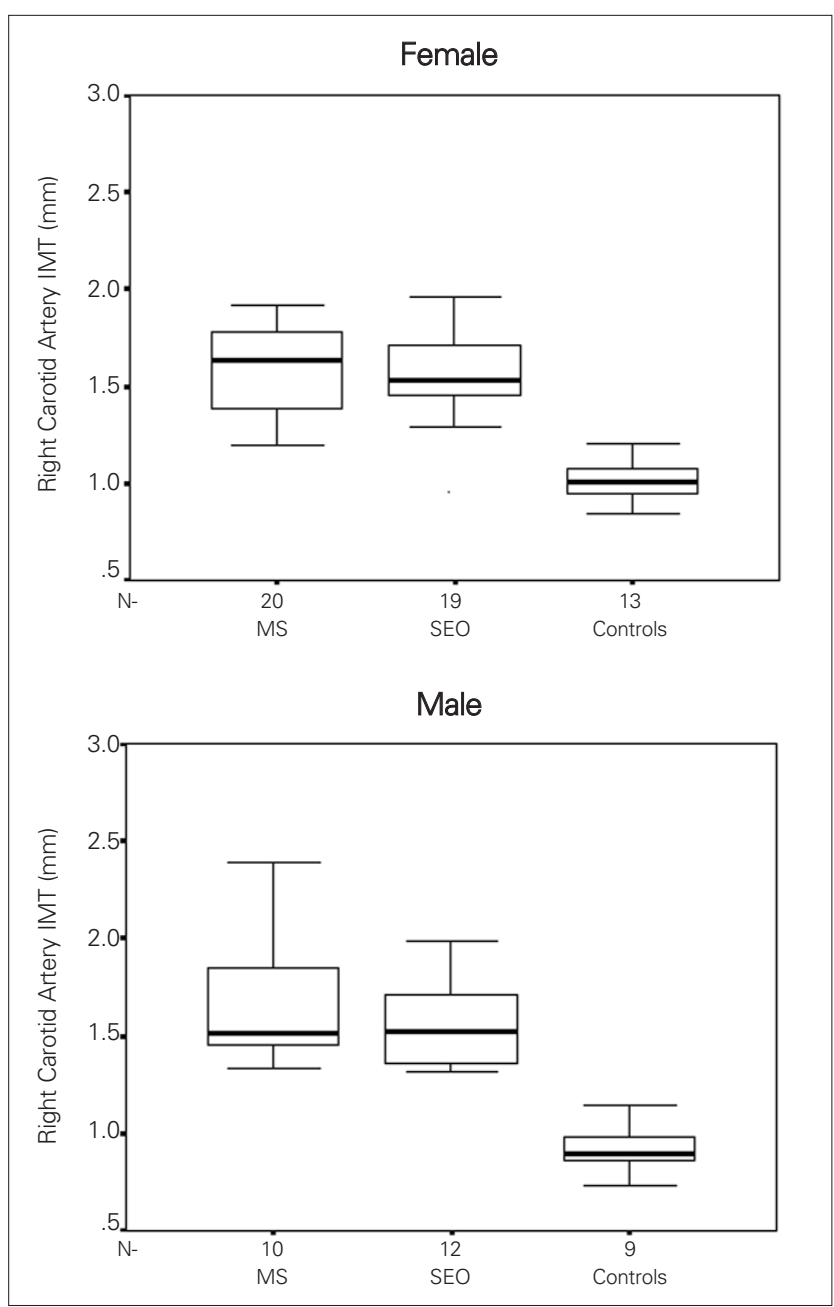

Figure 1. The right carotid artery intima-media thickness (IMT) of the obese groups and controls

*Median, $25^{\text {th }}-75^{\text {th }}$ centiles, minimum and maximum values are denoted.

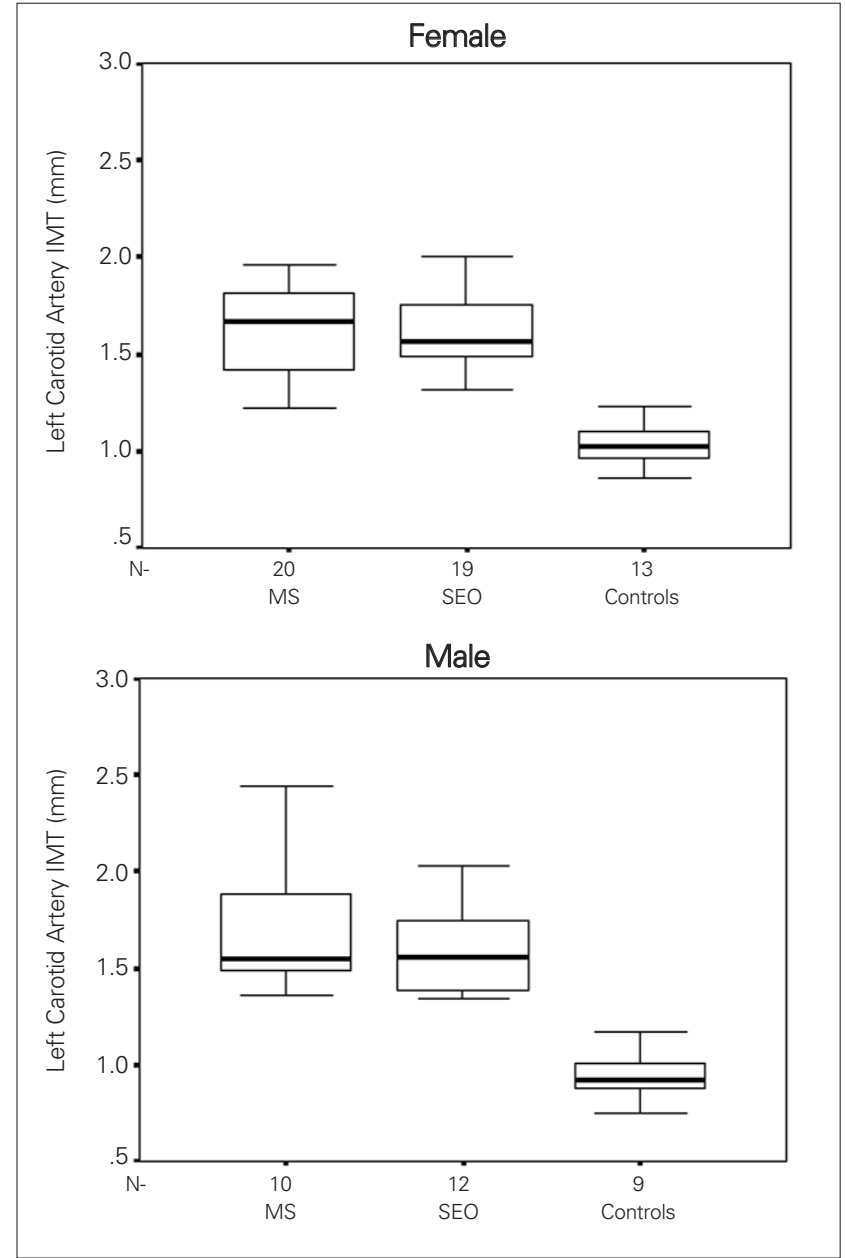

Figure 2. The left carotid artery intima-media thickness (IMT) of the obese groups and controls

* Median, $25^{\text {th }}-75^{\text {th }}$ centiles, minimum and maximum values are denoted.

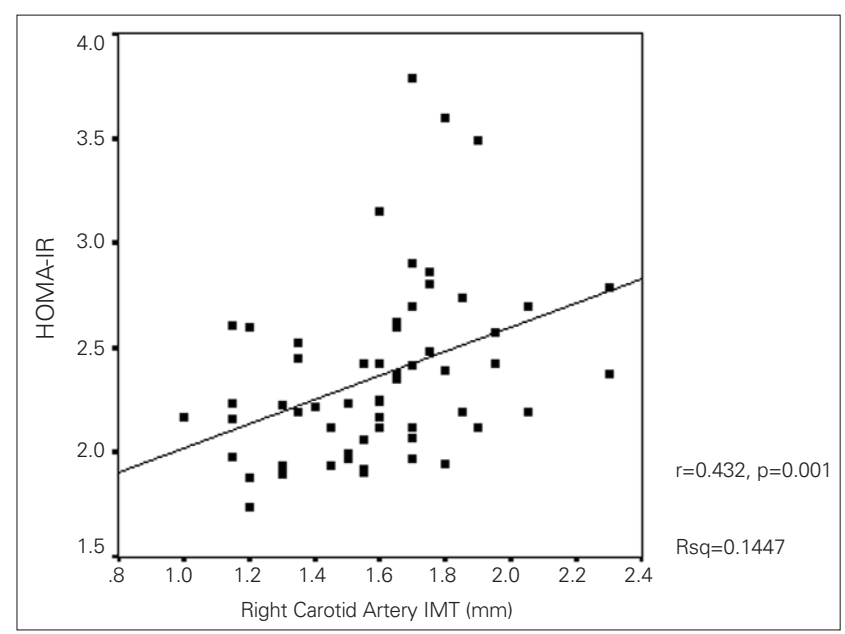

Figure 3. Correlation between right carotis artery intima-media thickness (IMT) and hoemostatic model assessment for insulin resistance (HOMA-IR) 
Table 4. Multivariate linear regression results for QTC

\begin{tabular}{llllll}
\hline Parameters & Beta (B) & SE (B) & T & p & F \\
\hline Right carotid artery IMT & -0.251 & 0.12 & $-2,027$ & 0.048 & 5,068 \\
Chronological age & -0.299 & 0.01 & $-2,392$ & 0.020 & \\
HDL-C & -0.253 & 0.000 & 2,038 & 0.047 & \\
Adjusted R ${ }^{2}=0.182$ & & & & \\
\hline IMT: Intima-media thickness, OTc: corrected OT & & & & \\
\hline
\end{tabular}

Table 5. Multivariate linear regression results for right carotid artery intima-media thickness

\begin{tabular}{llllll}
\hline Parameters & Beta (B) & SE (B) & T & p & F \\
\hline Left carotid artery IMT & 0.624 & 0.089 & 6.327 & $<0.001$ & 28.062 \\
BMI & 0.234 & 0.005 & 2.370 & 0.021 & \\
Adjusted R ${ }^{2}=0.496$ & & & & \\
\hline IMT: Intima-media thickness, OTc: corrected OT & & &
\end{tabular}

in obese children with or without MS. We suggest routine electrocardiographic control in obese children, even in those who are free of symptoms.

Although the relationship between endothelial dysfunction and obesity-related insulin resistance remains unclear, they frequently coexist. Several possible mechanisms between insulin resistance and endothelial dysfunction have been suggested, such as increased production of triglycerides (TG) and impaired endothelium-dependent vasodilatation. Endothelial dysfunction is also well correlated with abdominal obesity (33). Besides, increased LDL-C, lower HDL-C, insulin resistance, hypertension, smoking and obesity are well known cardiovascular risk factors, and the relationship between increased abdominal fat mass and these factors are well documented (14). These risk factors in childhood may induce changes in the arteries contributing to the development of atherosclerosis in adulthood. The measurement of carotid artery IMT is a non-invasive and reliable method for screening the early atherosclerotic changes. Increased carotid artery IMT might be a predictive marker for coronary artery disease. We found that IMT of both carotid arteries became thicker in prepubertal obese children.

The results of this study also indicate that RCA-IMT can be significantly affected by BMI and LCA-IMT. Sorof et al (34) reported that overweight and hypertensive children have higher carotid IMT than healthy children. In the present study, no significant difference in IMT of the obese children with and without MS was found, while IMT of both carotid arteries were higher than the controls in both obese groups. However, SBP of the obese children with MS was higher than that of the SEO group. These results suggest that obesity is a significant factor for developing atherosclerosis, even if other components of MS such as hypertriglyceridemia and hyperinsulinemia are not present. Oalmann et al (35) have demonstrated that cardiovascular risk factors such as hypertension, obesity, hypercholesterolemia have a role in preclinical atherosclerosis in children. It was reported in the Bogalusa Heart Study that obese children with higher IMT become obese adults, while obese children with normal IMT have normal weight in adulthood (3).

This study has some limitations. It is a cross-sectional study and the study population consists of children who were referred for obesity. A cross-sectional study design does not prove causality. IMT could be influenced by some hereditary factors, such as HDL-C level, and Turkish people have lower HDL-C levels (36). However, our study showed that HDL-C levels of the controls were higher than those of the obese children with MS.

In conclusion, significant differences in QTC and IMT of both carotid arteries between obese children and healthy controls were observed in this study. Obese children must be followed closely for early cardiovascular disorders, even in the absence of clinical symptoms.

\section{References}

1. Must A, Jacques PF, Dallal GE, Bajema CJ, Dietz WH. Long-term morbidity and mortality of overweight adolescents. A follow-up of the Harvard Growth Study of 1922 to 1935. N Eng J Med 1992;327:1350-1355. [Abstract] / [Full Text]

2. Power C, Lake JK, Cole TJ. Measurement and long-term health risk of child and adolescent fatness. Int $\mathrm{J}$ Obes Relat Metb Disord 1997;21:507-526. [Abstract] / [PDF]

3. Freedman DS, Dietz WH, Srinivasan SR, Berenson GS. The relation of overweight to cardiovascular risk factors among children and adolescents: The Bogalusa Hearth Study. Pediatrics 1999;103:1175-1182. [Abstract] / [Full Text] / [PDF]

4. Kannel WB, Plehn JF, Cupples LA. Cardac failure and sudden death in the Framingham Study. Am Heart J 1998;115:869875. [Abstract] 
5. Pringle TH, Scobie IN, Murray RG, Kesson CM, Maccuish AC. Prolongation of the QT interval during therapeutic starvation: a substrate for malignant arrhythmias. In J Obes 1983;7:253261. [Abstract]

6. el-Gamal A, Gallagher D, Nawras A, Gandhi P, Gomez J, Allison DB, Steinberg JS, Shumacher D, Blank R, Heymsfield SB. Effects of obesity on QT, RR and QTc intervals. Am J Cardiol 1995;5:956-959. [Abstract] / [PDF]

7. Carella MJ, Mantz SL, Rovner DR, Willis PW, Gossain VV, Bouknight RR, Ferenchick GS. Obesity, adiposity, and lengthening of the QT interval: improvement after weight loss. Int J Obes 1996;20:938-942. [Abstract]

8. Soydinc S, Davutoglu V, Akcay M. Uncomplicated metabolic syndrome is associated with prolonged electrocardiographic QTc interval and QTc dispersion. A.N.E 2006;11:313-317. [Abstract] / [Full Text] / [PDF]

9. Gastaldelli A, Emdin M, Conforti F, Camastra S, Ferrannini E. Insulin prolongs the QTc interval humans. Am J Physiol Regul Integr Comp Physiol 2000;279:2022-2025. [Abstract] / [Full Text] / [PDF]

10. Suys BE, Huybrechts SJ, De Wolf D, Op De Beeck L, Matthys D, Van Overmeire B, Du Caju MV, Rooman RP. QTc interval prolongation and QTc dispersion in children and adolescents with type 1 diabetes. J Pediatr 2002;141:59-63. [Abstract] / [Full Text] / [PDF]

11. Gary TC, Chan JCN, Critchley JAJH, Cockram CS. Cardiovascular disease in Chinese type 2 diabetic women is associated with a prolonged OTc interval. Int J Cardiol 2000;76:75-80. [Abstract] / [Full Text] / [PDF]

12. Christensen PK, Gall MA, Major-Pedersen A, Sato A, Rossing $P$, Breum L, Pietersen A, Kastrup J, Parving HH. QTc interval length and QTc dispersion as predictors of mortality in patients with non-insulin dependent diabetes. Scand Clin Lab Invest 2000;60:323-332. [Abstract] / [PDF]

13. Tounian P, Aggoun Y, Dubern B, Varille V, Guy-Grand B, Sidi D, Girardet JP, Bonnet D Presence of increased stiffness of the common carotid artery and endothelial dysfunction in severely obese children: a prospective study. Lancet 2001; 358:1400-1404. [Abstract] / [Full Text] / [PDF]

14. Berenson GS, Sathanur RS, Bao W, Newman WP, Tracy RE, Wattigney WA. Association between multiple cardiovascular risk factors and atherosclerosis in children and young adults. N Eng J Med 1998;338:1650-1656. [Abstract] / [Full Text] / [PDF]

15. Mahoney LT, Burns TL, Stanford W, Thompson BH, Witt JD, Rost CA, Lauer RM. Coronary risk factors measured in childhood and young adult life are associated with coronary artery calcification in young adults: the Muscatine Study. J Am Coll Cardiol 1996;27:277-284. [Abstract]

16. Gunnell DJ, Frankel SJ, Nanchahal K, Peters TJ, Davey Smith G. Childhood obesity and adult cardiovascular mortality: a 57-y follow-up study based on the Boyd Orr cohort. Am J Clin Nutr 1998;67:1111-1118. [Abstract] / [PDF]

17. Craven TE, Ryu JE, Espeland MA, Kahl FR, McKinney WM, Toole JF, McMahan MR, Thompson CJ, Heiss G, Crouse JR 3rd. Evaluation of the associations between carotid artery atherosclerosis and coronary artery stenosis. Acase-control study. Circulation 1990;82:1230-1242. [Abstract] / [PDF]

18. Crouse JR III, Craven TE, Hagaman AP, Bond MG. Association of coronary disease with segment-specific intimal-medial thicking of the extracranial carotid artery. Circulation 1995;92:1141-1147. [Abstract] / [Full Text]

19. Crouse III JR,Tang R,Espeland MA, Terry JG, Morgan T, Mercuri M. Associations of extracranial carotid atherosclerosis progression with coronary status and risk factors in patients with and without coronary artery disease. Circulation 2002;106:2061-2066. [Abstract] / [Full Text] / [PDF]
20. O'Leary DH,Polak JF, Kronmal RA, Kittner SJ, Bond MG, Wolfson SK, Bommer W, Price TR, Gardin JM, Savage PJ. Distribution and correlate of sonographically detected carotid artery disease in the Cardiovascular Health Study. The CHS Colloborative Research Group. Stroke 1992;23:1752-1760. [Abstract] / [PDF]

21. Festa A, D'Agostino R Jr, Rautaharju P, O'Leary DH, Rewers M, Mykkanen L, Haffner SM. Is OT interval a marker of subclinical atherosclerosis in nondiabetic subjects? The Insulin Resistance Atherosclerosis Study (IRAS). Stroke 1999;30: 1566-1571. [Abstract] / [Full Text] / [PDF]

22. Bundak R, Furman A, Gunoz H, Darendeliler F, Bas F, Neyzi O. Body mass index references for Turkish children. Acta Paediatr 2006;95:194-198. [Abstract] / [Full Text] / [PDF]

23. Meaney E, Alva F, Moguel R, Meaney A, Alva J, Webel R. Formula and nomogram for the sphygmomanometric calculation of the mean arterial pressure. Heart 2000;84:64. [Abstract] / [Full Text] / [PDF]

24. Tümer N, Yalcinkaya F, Ince E, Ekim M, Köse K, Çakar N, Kara N, Ozkaya N, Ensari C, Onder S. Blood pressure nomograms for children and adolescents in Turkey. Pediatr Nephrol 1999;13:438-443. [Abstract] / [PDF]

25. Bazett HC. An analysis of the time relationships of electrocardiograms. Heart 1920;7:353-357.

26. Schwartz PJ, Stramba-Badiale M, Segantini A, Austoni P, Bosi G, Giorgetti R, Grancini F, Marni ED, Perticone F, Rosti D, Salice P.Prolongation of the QT interval and the sudden infant death syndrome. N Eng J Med 1998;338;1709-1714. [Abstract] / [Full Text] / [PDF]

27. Friedewald WT, Levy RI, Fredrickson DS.Estimation of the concentration of low-density lipoprotein cholesterol in plasma without use of the preparative ultracentrifuge. Clin Chem 1972;18:499-502. [Abstract] / [PDF]

28. Keskin M, Kurtoglu S, KendirciM, Atabek ME, Yazici C. Homeostasis Model Assessment is more reliable than the fasting glucose ratio and Quantitative insulin sensitivity check index for assessing insulin resistance among obese children and adolescents. Pediatrics 2005;115;e500-e503.[Abstract] / [Full Text] / [PDF]

29. Katz A, Nambi SS, Mather K, Baron AD, Follmann DA, Sullivan G, Quon MJ. Quantitavive insulin sensitivity check index: a simple, accurate method for assessing insulin sensitivity in humans. J Clin Endocrinol Metab 2000;85:2402-2410. [Abstract] / [Full Text] / [PDF]

30. Cruz ML, Goran MI. The metabolic syndrome in children and adolescents. Current Diabetes Reports 2004;4:53-62. [Abstract] / [Full Text] / [PDF]

31. Weiss R, Dziura J, Burgert TS, Tamborlane WV, Taksali SE, Yeckel CW, Allen K, Lopes M, Savoye M, Morrison J, Sherwin RS, Caprio S. Obesity and the metabolic syndrome in children and adolescents. N Ena J Med 2004;350:2362-2374. [Abstract] / [Full Text] / [PDF]

32. Frank S, Colliver JA, Frank A. The electrocardiogram in obesity:statistically analysis of 1029 patients. J Am Coll Cardiol 1986;7:295-299. [Abstract] / [Full Text] / [PDF]

33. Yki-Jarvinen $\mathrm{H}$. Insulin resistance and endothelial dysfunction. Best Practice \& Research Clinical Endocrinology\&Metabolism 2003;17:411-430. [Abstract] / [Full Text] / [PDF]

34. Sorof JM, Alexandrov AV, Garami Z, Turner JL, Grafe RE, Lai D, Portman RJ. Carotid ultrasonography for detection of vascular abnormalities in hypertensive children. Pediatr Nephrol 2003;18:1020-1024. [Abstract] / [Full Text] / [PDF]

35. Oalmann MC, Strong JP, Tracy RE, Malcom TG. Atherosclerosis in youth: are hypertension and other coronary heart disease risk factors alreadv at work? Pediatr Nephrol 1997;11:99-107. [Abstract] / [PDF]

36. Uzunlulu M, Oguz A, Tigen K. High-density lipoprotein cholesterol in coronary artery disease patients: is it as low as expected? Anadolu Kardiyol Derg 2005;5:268-70. [Abstract] / [Full Text] / [PDF] 